\title{
Response to Letter to the editors referring to Fikenzer, S., Uhe, T., Lavall, D., Rudolph, U., Falz, R., Busse, M., Hepp, P., \& Laufs, U. (2020). Effects of surgical and FFP2/N95 face masks on cardiopulmonary exercise capacity. Clinical research in cardiology: official journal of the German Cardiac Society, 1-9. Advance online publication. https://doi.org/10.1007/s00392-020-01704-y
}

\section{Sven Fikenzer ${ }^{1}\left[\right.$. Ulrich Laufs ${ }^{1}$}

Received: 17 August 2020 / Accepted: 19 August 2020

(c) The Author(s) 2020, corrected publication 2021

Response to Petru et al.

Sirs:

$\mathrm{VO}_{2 \mathrm{RCP}}$ and $\mathrm{relVO} \mathrm{V}_{2} \mathrm{max}$ at RCP were significantly reduced for ffpm. Please find the detailed values below. The method for the quantification of ten domains of comfort/discomfort of wearing a mask (humidity, heat, breathing resistance, itchiness, tightness, saltiness, feeling unfit, odor, fatigue, and overall discomfort) is described in the manuscript.

The clear results of our study show that ventilation, cardiopulmonary exercise capacity, and comfort are reduced by surgical masks and highly impaired by FFP2/N95 face masks in healthy individuals. Future/ongoing studies need to address the effects during long-term sub-maximal physical activity and in patients with pulmonary and/or cardiac diseases.

We strongly believe that medical recommendations need to be based on evidence with regard to risk and benefit. As an example, the knowledge about adverse effects associated with many live-saving medications (e.g., immunosuppressant drugs) is a prerequisite for adequate treatment recommendations and long-term success.

This reply refers to the comment available online at https://doi. org/10.1007/s00392-020-01735-5.

Sven Fikenzer

sven.fikenzer@medizin.uni-leipzig.de

1 Universitätsklinikum Leipzig, Leipzig, Germany $\underline{\text { VO }}_{\underline{2 R C P}}$

$\mathrm{nm}: 2468 \pm 514 \mathrm{ml} / \mathrm{min}$

sm: $2401 \pm 662 \mathrm{ml} / \mathrm{min}$

ffpm: $2242 \pm 535 \mathrm{ml} / \mathrm{min}$

one-way ANOVA $p=0.044$

nm vs. $\operatorname{sm} p=0.707$

nm vs. $\operatorname{ffpm} p=0.017$

$\underline{\mathrm{relVO}}_{2} \underline{\max \text { at RCP }}$

$\mathrm{nm}: 75.5 \pm 5.5 \%$

sm: $72.8 \pm 7.8 \%$

ffpm: $68.5 \pm 7.2 \%$

one-way ANOVA $p=0.034$

nm vs. $\operatorname{sm} p=0.486$

nm vs. ffpm $p=0.017$

Sven Fikenzer and Ulrich Laufs.

Open Access This article is licensed under a Creative Commons Attribution 4.0 International License, which permits use, sharing, adaptation, distribution and reproduction in any medium or format, as long as you give appropriate credit to the original author(s) and the source, provide a link to the Creative Commons licence, and indicate if changes were made. The images or other third party material in this article are included in the article's Creative Commons licence, unless indicated otherwise in a credit line to the material. If material is not included in the article's Creative Commons licence and your intended use is not permitted by statutory regulation or exceeds the permitted use, you will need to obtain permission directly from the copyright holder. To view a copy of this licence, visit http://creativecommons.org/licenses/by/4.0/. 